\title{
Static and dynamic calculations of suspended monorails' selected parameters
}

\author{
Eukasz BOEOZ ${ }^{1 *}$
}

\author{
Authors' affiliations and addresses: \\ ${ }^{1}$ AGH University of Science and Technology, \\ Department of Machinery Engineering and \\ Transport, A. Mickiewicza Av. 30, 30-059 \\ Krakow, Poland, \\ e-mailboloz@agh.edu.pl \\ *Correspondence: \\ Łukasz Bołoz, AGH University of Science and \\ Technology, Department of Machinery \\ Engineering and Transport, A. Mickiewicza \\ Av. 30, 30-059 Krakow, Poland, \\ e-mail boloz@agh.edu.pl \\ How to cite this article: \\ Bołoz, Ł. (2021). Static and dynamic \\ calculations of suspended monorails' selected \\ parameters. Acta Montanistica Slovaca, \\ Volume 26 (3), 566-581 \\ DOI: \\ https://doi.org/10.46544/AMS.v26i3.14
}

\begin{abstract}
The exploitation of mineral resources is inextricably linked with mine transportation. Various means of transport are used in underground mines, including suspended monorails, which have been commonly applied in recent years. Suspended monorails are used to transport people and materials in horizontal and inclined workings. According to the regulation of the Minister of Energy in force in Poland, the documentation of the suspended monorail transportation system must take into account traction calculations. However, there are no detailed guidelines regarding calculations confirming the correct selection of the means of transport for a specific excavation. The regulation of the Minister of Energy contains only a few general guidelines. Due to the lack of detailed guidelines, mine employees use various calculations that are not supported by an appropriate method. Therefore, in response to the needs of mines, a method for performing static and dynamic calculations of suspended monorails' selected traction parameters has been developed. The method, among others, enables calculating the permissible transported mass for the given angle of excavation inclination and the tractive force of the set, as well as verifying the static and dynamic load for single support frames during the ride of the suspended monorail in any configuration. The calculations are carried out for braking with a locomotive and with emergency braking trolleys. The method was developed at the Department of Machine Engineering and Transport at AGH University of Science and Technology in Cracow. The calculation method in question has been presented and described in this article. It was implemented in April 2020 in one of the Polish mines and is successfully applied to carry out calculations for all workings. The mine uses a specially developed calculation sheet, which is directly attached to the documentation of the transport system. The spreadsheet allows for entering data and obtaining results without interfering with the calculation method. In 2020, the calculation sheet was applied to prepare calculation documentation for routes in several workings. The experience of mine employees confirms its usefulness, and the mining office has no objections to the developed method.
\end{abstract}

\section{Keywords}

suspended monorails, traction calculations, calculation method, calculation spreadsheet, static and dynamic calculations 


\section{Introduction}

Mine transportation is an essential element of the mining process in any mining plant. The overhead rail transportation system was applied relatively late compared to floor transportation. Due to the manner of their installation, suspended monorails are more demanding. The transportation set moves along a rail suspended on chains that are attached to the yielding arch support of the roadway, popularly known and marked as ŁP. The rails consist of sections of a certain length. Modern railways have their own Diesel engines or electric drives and are equipped with all the necessary elements, including trolleys, drives, emergency braking trolleys, engine room, operator's cabin, as well as various types of transport beams (Antoniak, 1980).

Various types of transport beams are intended for the transportation of materials, and, with benches installed, also for the transportation of people. The elements of the set are connected with each other by means of pushing rods. A transportation set having a specific length, unladen weight, and transported weight loads the ŁP roadway support (Blatnicky, 2020). Depending on the specific location, the roadway may be horizontal or sloping. The resultant load acting on the support in the vertical plane passing through the rail is mainly due to the weight of the set components and the braking force.

Documentation regarding the suspended monorail transportation system is prepared in accordance with the Regulation of the Minister of Energy (on detailed requirements for the operation of underground mining plants of 23 November 2016, Journal of Laws of 2017, item 1118 as amended) $\S 630$ point 5. Since the implementation of the previously cited regulations, the approval of various kinds of documentation related to the transportation systems has been the responsibility of the Mining Plant Maintenance Manager. Properly prepared documentation includes, among others: traction calculations, i.e. braking distances and maximum transported useful weights, taking into account the permissible loads of connecting, load-bearing and securing elements. These calculations are the biggest problem for mining plant teams that prepare transport documentation. There are no readily available guidelines for performing calculations necessary to confirm the correct selection of the means of transport, in particular the ones regarding dynamic loads (including the transportation of people) (Draganová et al., 2020) and their prediction (Semrád et al., 2020), and the specialist literature in this area is not large (Figiel and Klačková, 2020). Due to the above-mentioned reasons, the mine initiated cooperation with the Department of Machinery Engineering and Transport of the AGH University of Science and Technology in Krakow, the purpose of which was to develop a new calculation method.

Transporation by overhead railways as well as the machines and devices themselves were described in the literature quite a long time ago (Antoniak, 1980). Numerous scientific articles have been devoted to the development of mine transportation, suspended monorails or selected aspects of this transportation, such as the development of Diesel or electric drives (Pieczora, 2008), (Pieczora and Suffner, 2013), (Pieczora and Suffner, 2017). Overhead monorails are a typical example of modular machines that can be easily reconfigured, which brings measurable benefits (Turygin et al., 2019), (Brahimi et al., 2019), (Alix et al., 2019). Only a few literature items can be found in the field of static and dynamic loads in suspended monorails. Some of them concern static and dynamic models and the impact of load on the rails in the case of suspended monorails in underground mining (Gutarevych, 2012), (Gutarevych, 2014), (Chanda and Besa, 2011). There are also articles on overground monorails (Lee et al., 2005). However, they contain only selective analyses, and the resulting formulas are not sufficient to perform the required calculations, especially in light of the regulations in force. There are also studies on wheel-rail cooperation in terms of dynamics (True, 2009) as well as stresses (Muravey et al., 2019). In one of the articles, the authors presented the results of FEM research on the impact of driving speed on the support load and the behaviour of transported people (Tokarczyk and Kania, 2016). In another article, one of the authors also used FEM calculations to present the impact of selected braking parameters on the transported people (Tokarczyk, 2016). In one of the works, the authors analysed vibrations in the operator's and passenger's cabin (Szewerda, 2020). Another publication concerns empirical studies of forces in rail lifting slings and accelerations acting during the ride and braking of suspended monorails (Tokarczyk et al., 2020). The latest literature also quotes the results of laboratory tests of the strength of the roadway support elements subjected to the load resulting from the use of suspended monorails (Pytlik, 2019). However, empirical studies and FEM are not applicable in this case. The most extensive work dealing with the parameters of suspended monorails in the conditions of Polish underground mines is the study presenting a proprietary solution of computer-aided selection of monorails (Kuric, 2021). This software enables configuring the required elements and checking the compliance of parameters, especially in terms of the required tractive force and total weight as well as the useful weight of the set (Tokarczyk and Dudek, 2020). Unfortunately, it is not possible to verify the load that the monorail elements transfer to the roadway support or to check other values related to braking.

A review of the literature in this field and interviews with mine employees have demonstrated that there are no currently available studies on the calculation of traction parameters in accordance with the regulations in force in Poland.

The calculation method in question is based on the developed physical and mathematical model of the transport system with a suspended monorail. When developing the model, the key assumptions were made based 
on an analysis of the technical documentation of machines and devices and the documentation of the transportation system. Moreover, in order to confirm the assumptions, a community interview was conducted with the employees responsible for the design and development of galleries (Kuric and Tlach, 2021). The developed method is consistent with the regulations in force in Poland and allows for calculating all values specified in these regulations. Based on this method, a calculation sheet was created. The method, along with the calculation sheet, was implemented in May 2020 in one of the Polish mines and has since been used to prepare calculation documentation for routes in several workings. The experiences of mine employees confirm its effectiveness, and the mining office has not raised any objections to it (Bołoz et al., 2020).

\section{Description of the transport system in the analysed mine}

Depending on whether they are used to transport only people, or also materials, especially longwall support units, the monorails in the analysed mine have various configurations and are available with 4, 5 or 6 friction drives, sometimes also with attached gear drives. In addition, 3, 4, 5 or 6 transport beams are used for the transportation of materials. In the event people are transported, these beams have suspended 8-person benches. A heavy beam and braking trolleys are used to transport powered support units. In the system transporting powered support, one heavy beam, also known as a high-load lifting beam, is applied. All driving units are adapted to work in non-methane and methane underground mining excavations as well as in underground mining excavations categorised as the class "a", "b", or "c" methane explosion hazard. The monorail engines are adapted to work in underground mine workings categorised as the class " $\mathrm{A}$ " or " $\mathrm{B}$ " coal dust explosion hazard. The driving units also meet the requirements of the current standards and regulations applicable to their usage in underground coal mining plants. Transportation sets of suspended friction monorails move along rails made of profile I155 according to the Polish standard or profile I140E according to the DIN standard, with a length of up to $2000 \mathrm{~mm}$. The rails are suspended from support on joints. Suspended monorails are used for the transportation of both materials and people. Transportation systems produced by FERRIT (Ferrits.r.o.), SCHARF (SMT Scharf AG) and BECKERWARKOP (Becker-Warkop Sp.z o.o.) are applied (Bołoz et al., 2020).

\section{Regulations and requirements in force in Poland}

The Regulation of the Minister of Energy on detailed requirements regarding the operation of underground mining plants of 23 November 2016 (Journal of Laws 2017, item 1118) provides only general requirements to be met by suspended monorail transportation systems. However, it does not specify how these calculations should be performed. Based on the analysis of the above-mentioned regulation, together with the appendices, all information regarding suspended monorails has been collected:

\section{$\S 122$ point 4 .}

The maximum resultant force generated by the monorail with cargo and load from other devices with which a single support arch can be loaded does not exceed $40 \mathrm{kN}$. The application of higher loads is permissible provided that calculations are made to confirm that the excavation support stability is maintained.

$\S 651$. point 1.

The carriage of people by suspended and floor-mounted monorails at speed greater than $2 \mathrm{~m} / \mathrm{s}$ is prohibited.

Appendix No. 4, points 4.9.8.

Braking trolleys operate automatically after exceeding by $50 \%$ the maximum permissible speed specified by their manufacturer in the operation and maintenance manual, but not more than $1 \mathrm{~m} / \mathrm{s}$, and have a static braking reliability coefficient of not less than 1.5 in relation to the maximum force rolling the transported unit specified in the documentation of the transportation system.

Appendix No. 4, points 4.9.9.

The self-propelled transportation set is equipped with a safety device to prevent the exceedance of the permitted speed. This device works automatically, also in the event of a power failure, after exceeding by $50 \%$ the maximum allowable speed of the drive specified by its manufacturer in the operation and maintenance manual, but not more than $1 \mathrm{~m} / \mathrm{s}$, and a static braking reliability coefficient of not less than 1.5 in relation to the maximum rolling force of the transported unit specified in the transport system documentation. It also ensures braking deceleration of not less than $1 \mathrm{~m} / \mathrm{s}^{2}$ and not more than $10 \mathrm{~m} / \mathrm{s}^{2}$.

Appendix No. 4, points 4.9.19.

Suspended and floor-mounted monorails' own drives intended for use in sloping headings with an inclination of not more than $45^{\circ}$ have a braking reliability coefficient, determined as the ratio of the maximum braking force to the maximum tractive force of own drive, of not less than 1.5, and cause that the braking deceleration of the transportation set is not less than $1 \mathrm{~m} / \mathrm{s}^{2}$ and not more than $10 \mathrm{~m} / \mathrm{s}^{2}$. 


\section{Assumptions for the calculation method}

The currently used suspended monorails have an increasing number of hydraulic drives. In the past, the standard was 4 drives, whereas now 6 drives are applied, sometimes with an additional gear drive. When the exploitation progresses to deeper levels where the slope of the deposit needs to be taken into account, monorails have to move along increasingly longer sections of workings with a significant slope. The input data for the project included the parameters of the transportation systems used, the workings' inclination, as well as broadly understood conditions and mining technologies used. It was assumed that this way, a calculation method and a related IT tool could be created. After the input data has been entered, the IT tool should provide ready results and compare them with values resulting from the regulations while providing information about the fulfilment or failure to fulfil the required conditions.

According to the requirements, the study was to concern selected traction calculations of suspended monorails and the calculations of forces loading individual support arches. The key elements of the method were the calculations of:

- permissible useful weight,

- admissible monorail load for the given angle of the excavation inclination based on the nomogram.

- the gravitational rolling force of the monorail for the set angle $\alpha$ at a maximum allowable load,

- initial braking velocity at the given angle $\alpha$, speed limiters response time and speed limits for brake activation,

- braking energy,

- effective braking force for the entire monorail, taking into account the longitudinal strength of the rails along the suspended monorail route,

- braking distance for the maximally loaded suspended monorail, for the monorail brakes and for the monorail equipped with braking trolleys,

- braking deceleration for the maximally loaded suspended monorail,

- braking reliability coefficient,

- dynamic load acting on the support during braking of a loaded suspended monorail that is distributed on the struts between the support arcs,

- permissible speed of a loaded suspended monorail (in accordance with the operation and maintenance instructions for the monorail),

- vertical static force generated by the monorail with material acting on a single support frame at the given inclination of the route and the deviation of the route sling chain from the vertical as well as dynamic force generated by the braking monorail with material acting on a single support frame.

According to the technology of yielding arch support installation, it is assumed that the support frame is loaded with the weight of the sling with the chain and the weight of the rail, as well as with the dead load of the set and the transported weight (material, crew including the operator). Additional equipment for the excavation is mounted to the frame on which the railway route is not suspended. The developed method took into account only machines and devices used and transported in the analysed mine.

The legislator does not specify safety factors or a calculation procedure in relation to the given limit value $F t_{\max }=40 \mathrm{kN}$ of the resultant load per single support frame. Therefore, it was assumed that the resultant computational value, taking into account specific and agreed assumptions, cannot be higher than the provided value, regardless of the direction and turn. The above-mentioned limit value may be increased to $50 \mathrm{kN}$ in accordance with the regulation; however, it must be confirmed by calculations.

\section{Calculation method}

The method of calculating selected parameters of suspended monorails is based on the developed physical and mathematical model. The key issue when calculating suspended monorail parameters is to determine the permissible total or useful load as well as the permissible driving speed of the set for a given tractive force and the angle of the excavation inclination. Both the load, in the form of mass, and speed are read from the nomograms provided by the manufacturer. Nomograms, which are created based on formulas describing the aforementioned relationships, constitute a mathematical model of the physical model of a suspended monorail set moving along a rail in an excavation with an inclination of $0^{\circ} \div 30^{\circ}$. A nomogram consists of graphs presenting two dependencies: travel speed versus tractive force (Fig. 1a) and a graph of transported mass as a function of tractive force and the angle of inclination of the excavation (Fig. 1b). Particular attention should be paid to the description of the graphs in the catalogue data because, depending on the manufacturer, the nomograms only apply to the useful or total weight. 

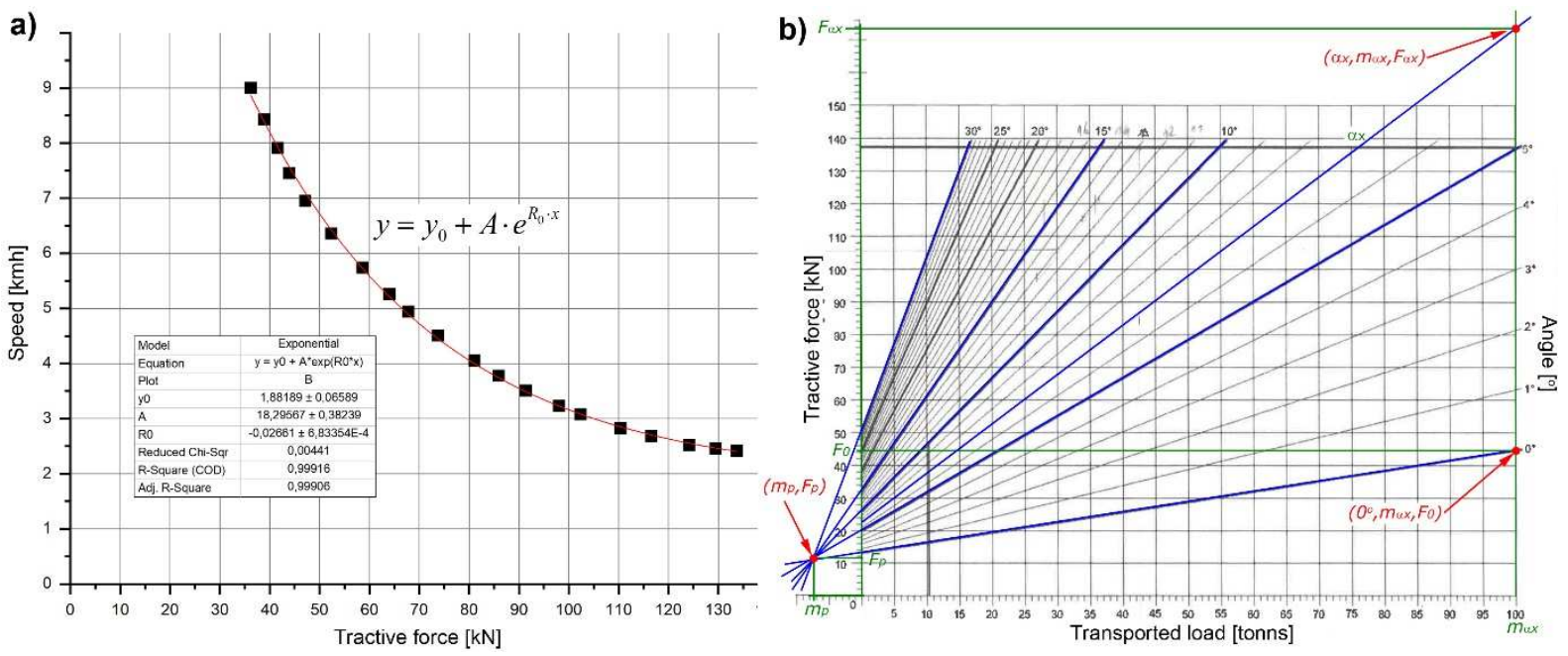

Fig. 1. Sample nomogram of a locomotive with 5 driving units:

a. graph of allowable speed versus tractive force,

b. graph of permissible transported mass versus tractive force and the angle of excavation inclination

The formula of the function describing the correlation between permissible speed and tractive force was developed using a suitable software for graph digitalising - "Engauge Digitizer" and an approximation software, for example, "OriginLab Origin Pro". Based on the analysis of a number of nomograms, it was found that the exponential function gives the best fit. Fig. 1a shows a sample course as well as the general formula of the function and coefficients obtained for this particular locomotive as a result of approximation.

The relationship between mass and tractive force, as well as the angle of the excavation inclination, is a function of two variables. Nomograms enable quick manual reading of the sought values in the function of two variables. A mathematical model of these relationships was developed so as to replace manual reading. The analysis of the nomograms of all the monorails used in the analysed mine allowed concluding that these relationships could be described by a pencil of lines with certain characteristics (Fig. 1b). Using the observed dependencies, the author derived a formula that enables calculating the permissible transported mass as a function of tractive force and the angle of excavation inclination. The final formula takes the following form:

$$
m\left(F_{p o c}, \alpha\right)=\frac{m_{\alpha x}-m_{p}}{F_{0}+\frac{F_{\alpha x}-F_{0}}{\alpha_{x}} \cdot \alpha-F_{p}}\left(F_{p o c}-F_{p}\right)+m_{p}
$$

where:

$m$ - desired value of the transported mass, $[\mathrm{kg}]$,

$F_{\text {poc }}$ - tractive force of the set $[\mathrm{N}]$,

$\alpha$ - excavation inclination angle, $\left[^{\circ}\right]$,

$F_{p}$ - abscissa of the vertex of the pencil, [N],

$m_{p}$ - ordinate of the vertex of the pencil, $[\mathrm{kg}]$,

$\alpha_{x}$ - maximum angle for which it is possible to read tractive force and mass, $\left[{ }^{\circ}\right]$,

$F_{0}-$ tractive force for mass $m_{\alpha x}$ and angle $0^{\circ},[\mathrm{N}]$,

$F_{\alpha_{x}}$ - tractive force for mass $m_{\alpha_{x}}$ and angle $\alpha_{x},[\mathrm{~N}]$,

$m_{\alpha x}-$ mass for tractive force $F_{\alpha x}$ and angle $\alpha_{x},[\mathrm{~kg}]$.

For each monogram, it is enough to determine and read the coordinates of 5 points from the graph $\left(m_{\alpha_{x}}, F_{0}\right.$, $F_{\alpha x}, F_{p}, m_{p}$ ), and after substituting them in formula (1), it is possible to calculate transported mass $m$ for any values of tractive force $F_{p o c}$ and excavation inclination angle $\alpha$. The developed general formula greatly facilitates the selection of a monorail.

The total mass and length of the set are calculated while taking into account the number of repeating elements, their weight and length. The length of an element is given as the distance between the axes of the fastening bolts, whereas the trolley spacing, which is needed at the load calculation stage, is given as the distance between the trolleys' symmetry axes. All the elements were analysed and summarised based on the technical documentation of the suspended monorails in the mine in question. All listed elements have a certain length and weight. The highest total load is generated by transport beams. The components related to the drive and control of the monorail include:

- cabin with a trolley (Fig. 2a),

- friction drive (Fig. 2b), 
- gear drive,

- auxiliary unit suspended under a single drive,

- auxiliary unit suspended under two drives (Fig. 2e),

- machine part (Fig. 2f).

The load is transferred to the rail by trolleys. Apart from these elements, single, duo or trio braking trolleys are used in sets with heavy beams (Fig. 2c). So-called GHB beams or SLG high-load beams are used to transport materials, whereas GHB beams are equipped with benches for the transportation of people. Therefore, there are three configurations for transporting people and materials:

- GHB beams,

- GHB beams with benches for the transportation of people (Fig. 2d),

- SLG high-load beam

The elements of suspended monorails are connected with each other by means of rigid pushing rods (Fig. $2 \mathrm{~g}$ ). A load of monorail components is usually transferred to the rail by one or two trolleys. The exception is the highload SLG beam, which has 8 trolleys.

a)

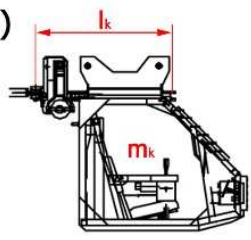

b)

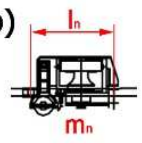

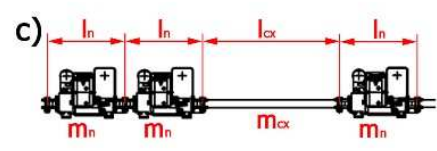

d)



e)

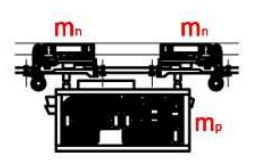

f)

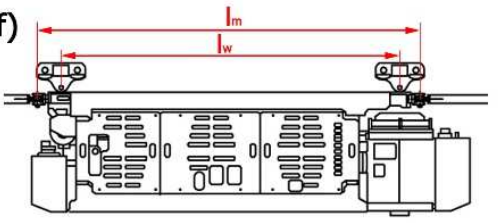

g)

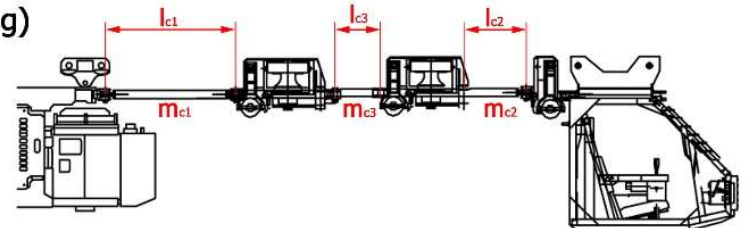

Fig. 2. Examples of marking the weight and length of monorail elements together with pushing rods: a. cabin with a trolley, $b$. friction drive,

c. trio trolley, $d$. GHB beam with benches for the transportation of people, e. weight of the auxiliary unit under two drives,

f. machine part, g. example of pushing rods marking

The rail consists of sections of a certain length $l_{s z}$. The load resulting from individual sets' dead load and transported weight is evenly distributed over the trolleys. However, as regards ultimate trolleys, the load resulting from the pushing rod weight should also be added. The forces generated by subsequent trolleys are transferred onto the rail. For the purposes of the model, the forces generated by two adjacent trolleys are marked as $P_{1}$ and $P_{2}$. The reaction forces in the chains on which the rails hang have been marked as $R_{l}$ and $R_{2}$. The diagram is shown in Fig. 3. In order to find the maximum load acting on the excavation support, the ride of the monorail over two rail sections should be analysed, taking into consideration only reaction $R_{2}$. From the point of view of mechanics, the highest load on chain $R_{2}$ can be calculated by finding the maximum of the function:

where:

$$
R_{2}=\max f\left(P_{1}, P_{2}, x_{v}, l_{w}\right)
$$

$R_{2}$ - vertical component of the reaction sought [N],

$P_{1}-$ vertical component of the first force which loads the rail [N],

$P_{2}$ - vertical component of the second force which loads the rail [N],

$x_{v}$ - position of the trolley in relation to the beginning of the rail, [m],

$l_{w}$ - spacing of trolleys $[\mathrm{m}]$.

In general, the rail is subject to loads from trolleys loaded with different forces $P_{1}$ and $P_{2}$. According to formula (2), depending on rail length $l_{s z}$, spacing $l_{w}$ and position of trolleys during the ride of the set, the load, i.e. reaction $R_{2}$ acting on the chain is variable. 


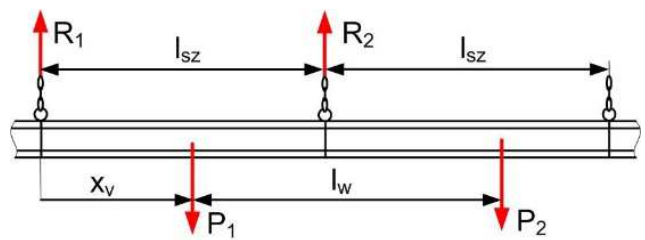

Fig. 3. Diagram for determining the maximum load on the chain

Based on the analysis of the monorails used, all calculation cases have been identified and summarised. There are five calculation cases for the entire length of the route (Fig. 4, Fig. 5). The first case (Wl) concerns a situation where the spacing of the trolleys is smaller than the rail length (Fig. 4a, b, c), whereas the second case (W2), a situation in which the spacing is greater than the rail length but not greater than twice the rail length (Fig. 4d, e, f). The third case (W3) occurs when the spacing of the trolleys is greater than twice the rail length (Fig. 5). The first two cases also have two subcases (W11, W12, as well as W21 and W22).
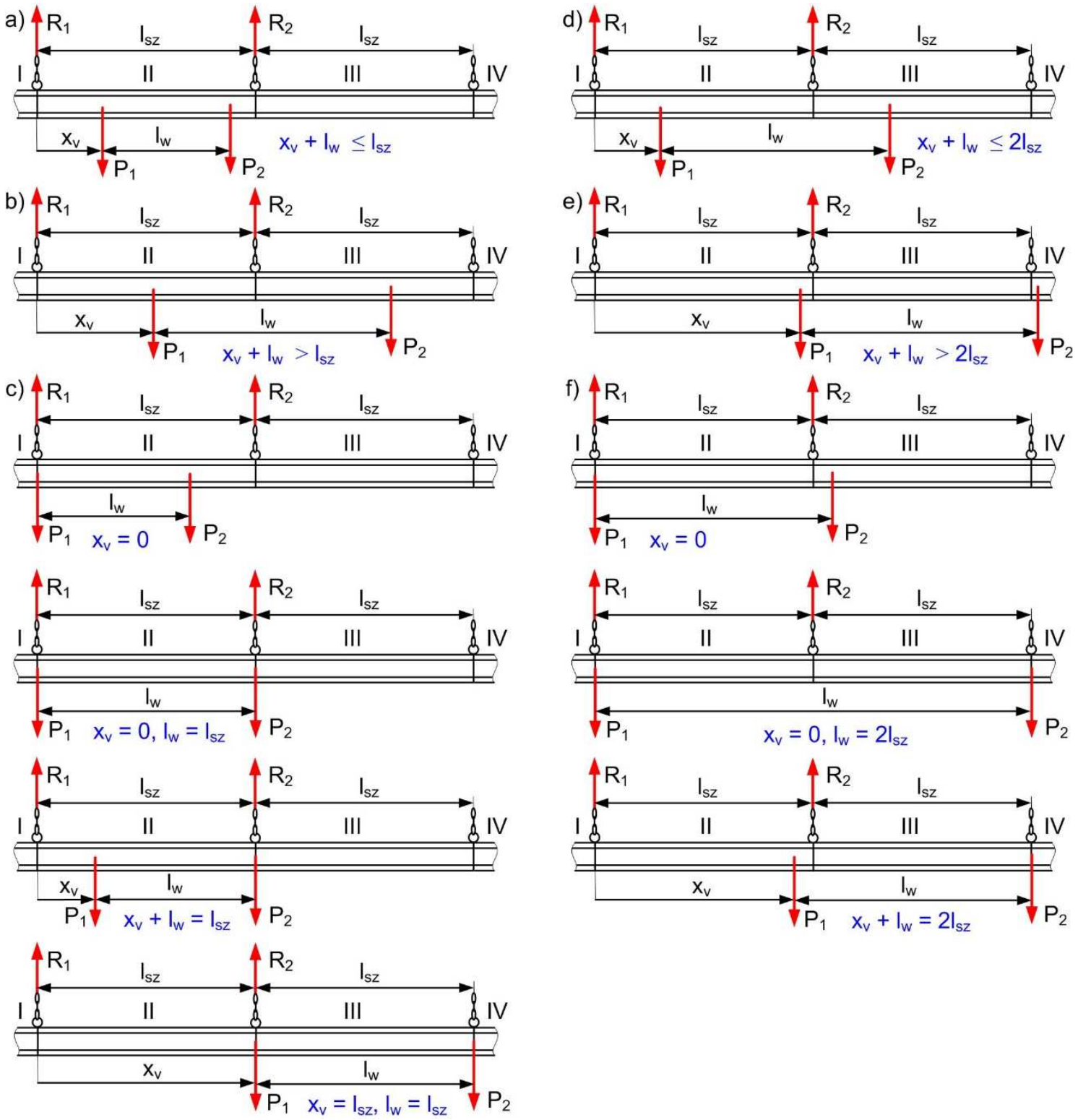

Fig. 4. Load cases for calculating the net force acting on the chain when the condition

$l_{w} \leq l_{s z}$ is fulfilled: $a$. condition $x_{v}+l_{w} \leq l_{s z}$ is fulfilled $b$. condition $x_{v}+l_{w}>l_{s z}$ is fulfilled c. special cases

$l_{s z}<l_{w} \leq 2 l_{s z}$ : $d$. condition $x_{v}+l_{w} \leq 2 l_{s z}$, is fulfilled e. condition $x_{v}+l_{w}>2 l_{s z}$ is fulfilled $f$. special cases 

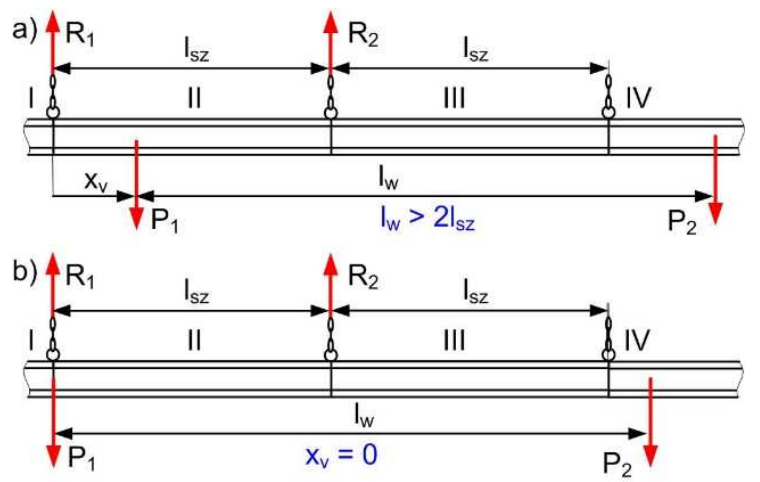

Fig. 5. Load cases for calculating the net force acting on the chain: a. the $l_{w}>2 l_{s z}$ condition is fulfilled $b$. special cases

Four sections of the rail were subjected to analysis, which allowed considering all the load cases. The attempts to find the highest load on the chain were based on the assumption that it would be at the end of rail II $\left(R_{2}\right)$. It was assumed that no trolley moved along the first rail. Trolleys run on the second rail, which is the most loaded one. The third and fourth rails take the load during the ride of the set, so the load on the second rail is successively reduced. The formulas were derived in order to calculate the forces acting on the chain at the ends of the second rail $\left(R_{1}, R_{2}\right)$ during the ride of the transportation set. The resultant force $R_{2}$ is the most important and the largest value.

The cases were determined analytically, hence 5 different sets of formulas were obtained. It should be emphasised that these 5 cases can be reduced to 3, as the final formulas in the second sub-case of the first case (W12) are identical with the formulas of the first sub-case in the second case $(W 21)$, i.e. $W 12=W 21$. Moreover, the equations $W 22$ and $W 3$ are equivalent.

All the possible cases have been listed below:

- condition Wl (Fig. 4 a, b, c) - the spacing of the trolleys is not greater than the rail length (condition $l_{w} \leq l_{s z}$ is fulfilled),

○ condition W11 (Fig. 4 a) - both trolleys move along rail II (condition $x_{v}+l_{w} \leq l_{s z}$ ) is fulfilled - formulas (2) and (3),

- condition $W 12$ (Fig. 4 b) - the first trolley moves along rail II, and the second one along rail III (condition $x_{v}+l_{w}>l_{s z}$ ) is fulfilled), formulas (4) and (5),

- condition $W 2$ (Fig. 4 d, e, f) - the spacing of the trolleys is greater than the rail length, but not greater than twice the rail length (condition $l_{s z}<l_{w} \leq 2 l_{s z}$ is fulfilled),

$\circ$ condition $W 21$ (Fig. $4 \mathrm{~d}$ ) - the first trolley moves along rail II and the second one along rail III (condition $x_{v}+l_{w} \leq 2 l_{s z}$ is fulfilled), formulas (4) and (5),

- condition W22 (Fig. 4 e) - one trolley moves along rail II and the other along rail IV (condition $x_{v}+l_{w}>2 l_{s z}$ is fulfilled), formulas (6) and (7),

- condition W3 (Fig. 5) - the spacing of the trolleys is greater than twice the rail length (condition $l_{w}>2 l_{s z}$ is fulfilled), formulas (6) and (7).

Fig. 4c, Fig. 4f and Fig. 5b present special cases, which enable quick verification of the derived formulas' correctness. For so specified conditions, it is possible to write the following formulas that allow calculating the values of forces in the chains of rail II as:

- condition W11:

$$
\begin{gathered}
R_{1}=P_{1}+P_{2}-\frac{P_{1} \cdot x_{v}+P_{2} \cdot x_{v}+P_{2} \cdot l_{w}}{l_{s Z}} \\
R_{2}=\frac{P_{1} \cdot x_{v}+P_{2} \cdot x_{v}+P_{2} \cdot l_{w}}{l_{s Z}}
\end{gathered}
$$

- $\quad$ conditions $W 12$ and $W 21$ :

$$
\begin{gathered}
R_{1}=P_{1}\left(1-\frac{x_{v}}{l_{s z}}\right) \\
R_{2}=P_{1} \cdot \frac{x_{v}}{l_{s z}}+P_{2}\left(2-\frac{l_{w}+x_{v}}{l_{s z}}\right)
\end{gathered}
$$

- $\quad$ conditions $W 22$ and $W 3$ : 


$$
\begin{array}{r}
R_{1}=P_{1}\left(1-\frac{x_{v}}{l_{s z}}\right) \\
R_{2}=P_{1} \cdot \frac{x_{v}}{l_{s z}}
\end{array}
$$

When making calculations, one should find the least favourable case. The spacing of trolleys between adjacent elements depends on the length of the pushing rods used (Pástor, 2020). Increasing the length of the pushing rod to a certain value reduces the load acting on a single chain. For example, for the SLG beam, the worst case may be between its ultimate trolley and the next trolley (middle SLG trolley). However, in the event a relatively short pushing rod is applied, the worst case may be observed for the ultimate SLG trolley and the trolley of the adjacent element, for example, a machine part.

It should be noted that the analysis, despite the fact that it was carried out for a horizontal excavation, the analysis is also correct for a heading inclined at an angle $\alpha$, which has been presented in Fig. 6 . The following formulas (8) and (9) are simple proof of this statement:

$$
\begin{aligned}
& \sum F=0 \Rightarrow R_{1}+R_{2}=P_{1}+P_{2} \\
& \sum M=0 \Rightarrow \\
& 0=-P_{1} \cdot x_{v} \cdot \cos (\alpha)-P_{2} \cdot\left(x_{v}+l_{w}\right) \cdot \cos (\alpha)+R_{2} \cdot l_{s z} \cdot \cos (\alpha) \\
& \Rightarrow 0=-P_{1} \cdot x_{v}-P_{2} \cdot\left(x_{v}+l_{w}\right)+R_{2} \cdot l_{s z}
\end{aligned}
$$

From the above relationships, one can derive formulas for reaction forces in which there is no excavation inclination angle. The inclination angle of the excavation will be taken into account when distributing the force between the rail and the support.

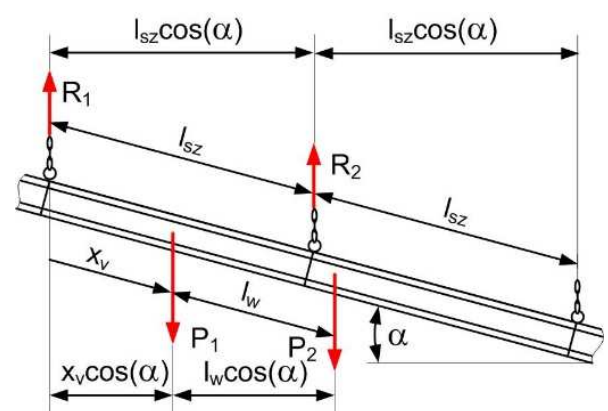

Fig. 6. Diagram of rail load for an inclined excavation

In further calculations, one should use the maximum value of force $R_{2}$, which for the analysed monorail configuration depends only on the position of the trolley in relation to rail $x_{v}$. The analysis should be conducted for the value of position $x_{v}$ ranging from zero to rail length $l_{s z}$, which allows for obtaining a full curse of the value of force $R_{2}$ during the monorail ride. The analysis aims to find maximum load $R_{2}$. The maximum force has been marked as $F$, therefore $F=R_{2}$. Assigning a lower value results in erroneous results of the support load.

The movement of the set along the rail is associated with resistance to motion. The set's resistance to motion always acts along the railway route, irrespective of the excavation inclination angle. Rolling resistance $F_{t t}$ was taken into account in the calculations. However, their influence was ignored due to the high efficiency of rolling bearings. Other kinds of resistance to the motion were also ignored. The rolling resistance formula can be written for the whole set as:

$$
F_{t t}=\frac{f}{R_{k}} \cdot m_{\text {zest }} \cdot g \cdot \cos (\alpha)
$$

where:

$F_{t t}$ - force of the set's resistance to motion, [N],

$f$ - rolling friction coefficient, it is assumed that $f=0.05 \mathrm{~mm},[\mathrm{~mm}]$,

$R_{k}$ - outer radius of the trolley pulley, it is assumed that $R_{k}=50 \mathrm{~mm},[\mathrm{~mm}]$,

$g$ - gravity acceleration $g=9.81 \mathrm{~m} / \mathrm{s}^{2},\left[\mathrm{~m} / \mathrm{s}^{2}\right]$. 
$m_{\text {zest }}-$ whole set mass, $[\mathrm{kg}]$.

The proposed, simplified model of resistance to motion, taking into account only the rolling friction, can be freely extended with further components that include, for example, the efficiency of the bearings or dirt on the rail. Likewise, the values of $f$ and $R_{k}$ should be adapted to the current situation. Resistance to motion has a marginal impact on the value of the load generated on the support. Fig. 7 shows a diagram of loading the rail with the force of gravity and resistance to motion and is used to determine the rolling force.

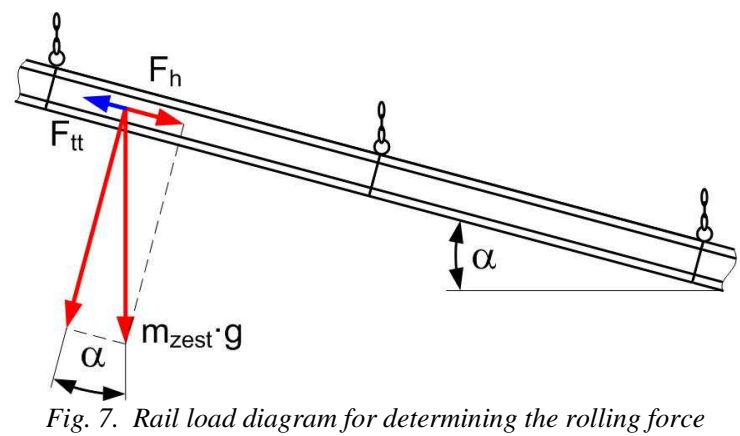

The formula for the rolling force of the set can be written as:

where:

$$
F_{h}=m_{z e s t} \cdot g \cdot \sin (\alpha)-F_{t t}
$$

$F_{h}-$ set's gravitational rolling force, [N].

The braking force of the set always acts along the railway route, regardless of the excavation inclination angle. The transportation set is equipped with drives installed on the drives and, sometimes, on cabins, which are used for braking by the operator. Additionally, the set may be equipped with braking trolleys for an emergency, automatic braking of the set. In order to distinguish and clearly separate calculations for braking by means of drives and braking with emergency trolleys, additional symbols in the subscripts are used during the calculations, for example, " $h$ " for braking with drives and " $w$ " for braking with emergency braking trolleys. In general, the braking force of the set in the case of braking with drives is:

where:

$$
F_{v}=F_{B} \cdot i_{B}
$$

$F_{v}$ - breaking force of the set in the case of braking with drives, [N],

$F_{B}$ - breaking force of a single brake, $[\mathrm{N}]$,

$i_{B}-$ number of brakes, [-].

In accordance with the requirements of the regulation, the following condition must be met for each set, both in the case of braking with drives and with emergency trolleys:

$$
\frac{F_{v}}{F_{\text {pocMAX }}} \geq 1,5
$$

The longitudinal force, in line with the direction of the railway route, acts on the joints of the rail sections. The forces acting alongside are the forces due to braking and resistance to motion. The longitudinal force is assumed to be transferred by the number of joints along the length of the set. Therefore, the following can be written:

$$
F_{z S z}=\frac{F_{v}+F_{t t}}{l_{z s z}} \leq F_{z S z M A X}
$$

where:

$F_{z s z}$ - longitudinal force in a single rail joint, [N],

$F_{z s z M A X}-$ admissible force in a single rail joint, [N],

$l_{z s z}$ - number of rail joints along the length of the set - value rounded down to the integer value, [-].

The derived formulas enable calculating the load of the rail and, in consequence, the chain load resulting from the force of gravity, braking and resistance to motion. Due to a slight difference between the load on the chain and the load on the support, the same larger value is assumed. The difference is only in the weight of the sling and the 
chain (Saga, 2020). It is assumed that the braking force is evenly distributed over each of the chains that are contained in the transportation set length. Fig. 8 shows a chain load diagram for determining the net force in the chain and, thus, the resultant force acting on a single frame of the ŁP support. The chain is subjected to the trolley's gravity load force, braking force and friction force. Due to the low height of the rail in relation to its length and joined connections of the rails with each other and with the chains, the forces generated by the rail were assumed to be transferred to the chain without any additional moment of force. Therefore, the resultant force that loads the chain, and, in consequence, the support, can be written as follows:

$$
F_{t}=F \cdot \cos (\beta)+\frac{F_{v}+F_{t t}}{l_{t}} \cdot \sin (\alpha+\beta)+\left(m_{z t}+m_{s z}\right) \cdot g \leq F_{t M A X}
$$

where:

$F_{t}$ - net force loading the ŁP support and the chain, [N],

$m_{z t}-$ weight of the sling and chain, $[\mathrm{kg}]$,

$m_{s z}-$ weight of the rail, $[\mathrm{kg}]$,

$F_{t M A X}$ - admissible net force loading the $Ł P$ support, $40 \mathrm{kN}$ or $50[\mathrm{kN}]$,

$\beta$ - angle of chain deviation from the vertical $\left[^{\circ}\right]$,

$l_{t}$ - chains along the set length - value rounded up to the total value [-].

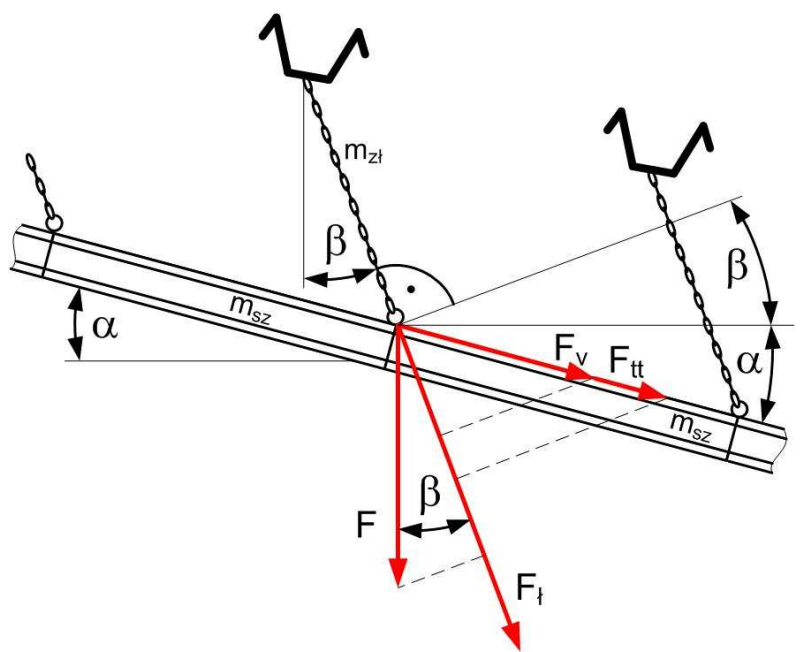

Fig. 8. Diagram for determining the resultant load of the chain and support

The resultant force loading the support can be distributed in such a way that the value of the force acting along the struts between the adjacent arches of the ŁP support can be obtained. Fig. 9 shows a diagram for deriving the formula for the total force in the struts $F_{r o z}$. This force must be transferred by a certain number of struts with an acceptable longitudinal force $F_{r o z M A X}$. In the analysed case, the permissible longitudinal force of the joint is 170 $\mathrm{kN}$. The angle of support's deviation from the vertical is half the angle of the excavation inclination, while the struts are parallel to the axis of the excavation. It was assumed that the entire load would be transferred by two struts, which is the least favourable but always fulfilled condition. If this value is exceeded, a model for struts load can be developed, which will enable determining their load depending on the arrangement on the perimeter of the support.

Therefore, the formula for the total longitudinal load can be written as follows:

$$
\begin{gathered}
F_{\text {roz }}=F_{t} \cdot \sin (\alpha+\beta) \\
i_{\text {rozMIN }}=\frac{F_{\text {roz }}}{F_{\text {rozMAX }}} \leq 2
\end{gathered}
$$

where:

$i_{\text {rozMIN }}$ - minimum number of struts, [-],

$F_{\text {rozMAX }}$ - permissible longitudinal force per one strut, $170 \mathrm{kN}$.

Additionally, formulas were derived to calculate: resultant braking deceleration, effective braking force, the velocity of the set at the beginning of braking, braking distance, braking time and braking energy. These values are also provided in the documentation of the transportation system in the excavation. Fig. 10 shows a diagram for deriving these quantities. 


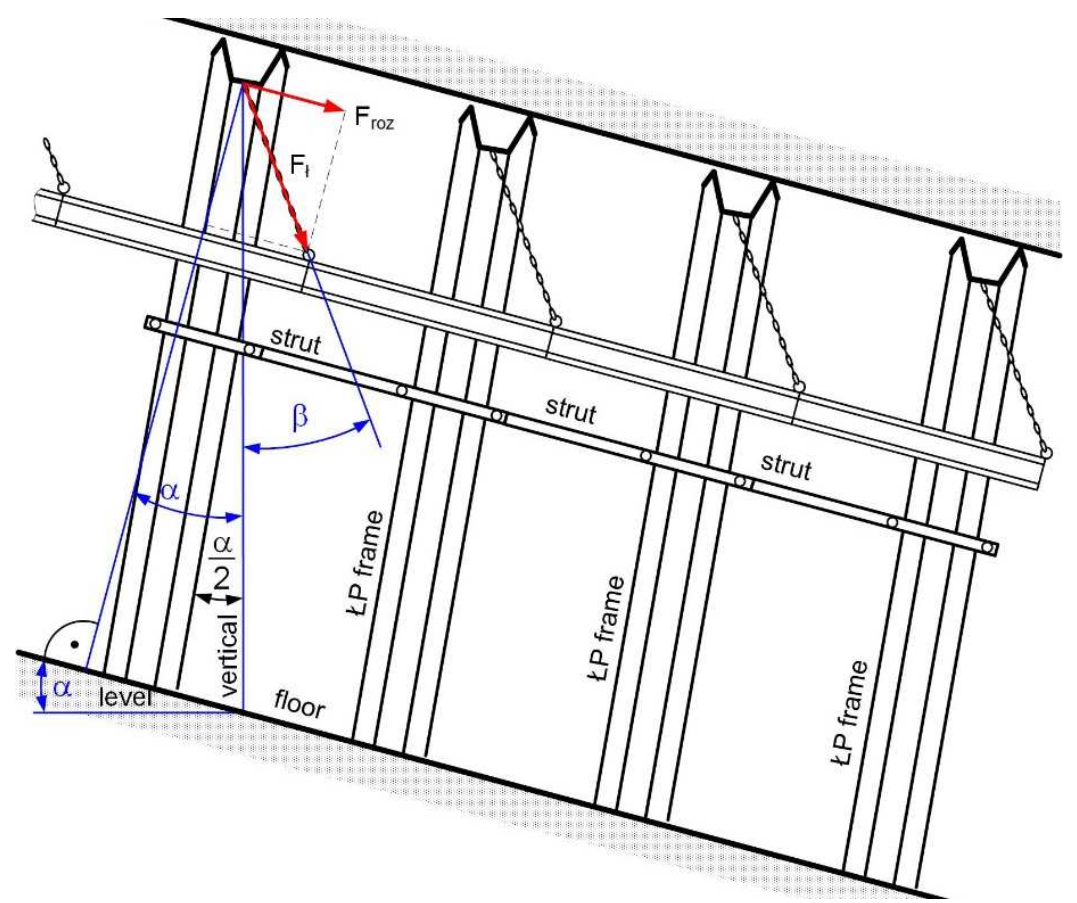

Fig. 9. Load diagram for calculating the load on the struts



Fig. 10. Diagram for deriving selected quantities during braking

The set is treated as one element of mass $m_{z e s t}$, which at the moment when the brakes are applied moves with velocity $v$. In the event of braking with emergency trolleys, velocity $\mathrm{v}$ at which the brakes are automatically activated must fulfil two conditions:

$$
\begin{gathered}
v \leq 1,5 \cdot v_{\text {max }} \\
v \leq\left(v_{\text {max }}+1 \frac{m}{s}\right)
\end{gathered}
$$

where:

$v$ - velocity at which emergency brakes are automatically activated, $[\mathrm{m} / \mathrm{s}]$,

$v_{\max }-$ speed limit read from the documentation, $[\mathrm{m} / \mathrm{s}]$.

The set is located in the excavation at an angle $\alpha$, so it is affected by gravity and resistance to motion. The delay due to resistance to motion can be calculated as follows:

where:

$$
a_{t t}=\frac{F_{t t}}{m_{z e s t}}
$$

$a_{t t}$ - delay of the set due to resistance to motion, [s/ $\left./ \mathrm{m}^{2}\right]$. 
Delay caused by braking force $a_{h}$ is:

where:

$$
a_{h}=\frac{F_{v}}{m_{z e s t}}
$$

$a_{h}$ - delay of the set due to braking force, $\left[\mathrm{m} / \mathrm{s}^{2}\right]$.

Delay due to braking force for both cases (drive brakes and emergency trolley brakes) must meet the following condition:

$$
1 \frac{m}{s^{2}} \leq\left(a_{h}\right) \leq 10 \frac{m}{s^{2}}
$$

Taking the above into account, the resultant braking deceleration $a_{w}$ can be calculated as follows:

where:

$$
a_{w}=a_{h}+a_{t t}-g \cdot \sin (\alpha)
$$

$a_{w}$ - resultant deceleration of the set, $\left[\mathrm{m} / \mathrm{s}^{2}\right]$.

Therefore, the effective braking force $F_{\text {ef }}$ is:

$$
F_{\text {ef }}=m_{\text {zest }} \cdot a_{w}
$$

where:

$F_{e f}$ - effective braking force, [N].

Due to delay in brake activation $t_{z}$, at the beginning of braking the set moves with velocity $v_{p}$ :

$$
v_{p}=v_{h}+\left(g \cdot \sin (\alpha)-a_{t t}\right) \cdot t_{z}
$$

where:

$v_{p}$ - velocity at which braking begins, $[\mathrm{m} / \mathrm{s}]$,

$t_{z}$ - delay in the activation of drive brakes, [s].

Also, due to a delay in brake activation, from the moment the brakes are activated to the moment they start working, the set will cover a certain distance, and, next, it will begin to slow down until it stops. Therefore, total braking distance $s_{h}$ is:

$$
s_{h}=v_{h} \cdot t_{z}+\frac{\left(g \cdot \sin (\alpha)-a_{t t}\right) \cdot t_{z}^{2}}{2}+\frac{v_{p}^{2}}{2 \cdot a_{w}}
$$

where:

$s_{h}-$ total braking distance, $[\mathrm{m}]$.

Similarly, the total braking time $t_{h}$ is:

where:

$$
t_{h}=t_{z}+\frac{v_{p}}{a_{w}}
$$

$t_{h}-$ total braking time, [s].

The end of braking means the stoppage of the set, i.e. reaching the zero velocity at which the set is at zero height, zero meaning the zero value of potential and kinetic energy.

Therefore, when the brakes start working, the set is at the initial height $h_{p}$ resulting from the braking distance that begins with velocity $v_{p}$ and finishes with the stoppage of the set. In such a situation, the set has kinetic energy related to velocity $v_{p}$ and potential energy related to height $h_{p}$, at which it is located. Taking the above into account, total braking energy $E_{h}$ can be written as follows:

$$
E_{h}=\frac{m_{\text {zest }} \cdot v_{p}^{2}}{2}\left(1+\frac{g \cdot \sin (\alpha)}{2 \cdot a_{w}}\right)
$$

where:

$E_{h}$ - braking energy, [J].

These formulas are applicable only if braking occurs, i.e. the resultant braking deceleration $a_{w}$ is greater than zero: 


$$
a_{w}>0 \Rightarrow \frac{F_{v}+F_{t t}}{m_{\text {zest }}}>g \cdot \sin (\alpha)
$$

Using a comprehensive calculation sheet, the presented calculation method enables obtaining all the values required by regulations. Fig. 11 shows the title page and the summary from the worksheet. These calculations apply to the excavation at the abandoned longwall No. 123 in the PG Silesia mine (Bołoz et al., 2020).
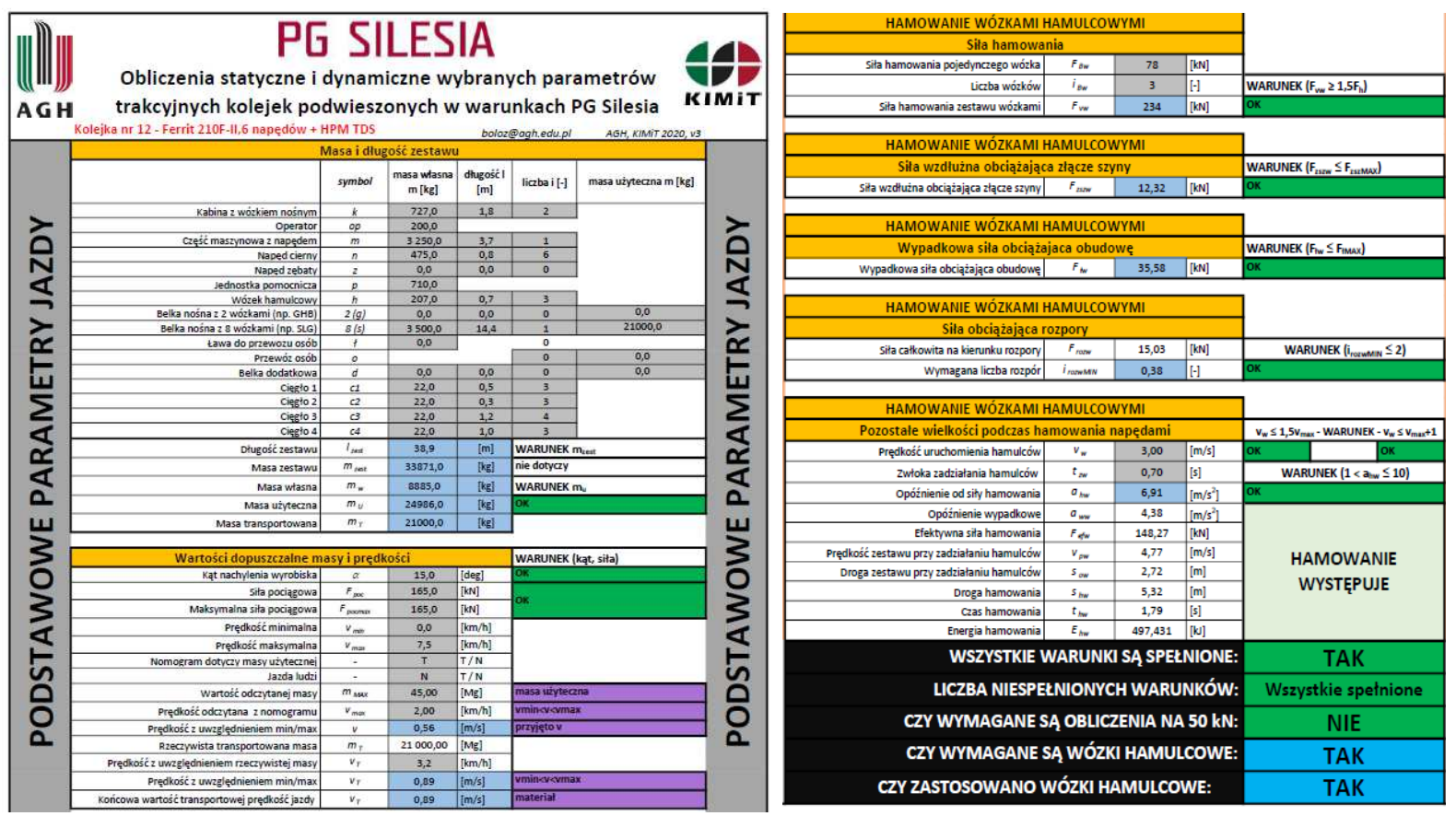
al., 2020)

Fig. 11. Title page and summary of calculations for the excavation in PG Silesia (original language of the calculation sheet) (Botoz et

\section{Summary}

The method for performing static and dynamic calculations of suspended monorails' selected traction parameters includes a precise description of the necessary calculations. Based on this method, a calculation sheet has been developed in which all calculations are performed automatically after entering the exact input data. The sheet additionally checks and informs about the fulfilment of all the required 19 conditions. If any of the conditions are not met, the sheet specifies which condition has not been fulfilled and provides the reason.

Persons designing suspended monorail transportation systems face three main problems, i.e. the increasing tractive force generated by the drives and their greater number as well as the weight of transported machines and devices with an increasing inclination of workings. It is also important to pay attention to special safety rules when transporting employees. Until present, performing calculations for several transportation sets moving in the transport system has been labour-intensive and, additionally, involved the risk of making a mistake. Thanks to the described method and IT tool, the calculation time has been significantly reduced, and a ready printout accompanies the documentation with the results of the calculations. Due to the security measures applied in the spreadsheet, it is only possible to enter input data consistent with the assumed ranges. The remaining part of the sheet is blocked. This ensures that the calculations are performed according to the same method each time. The sheet includes the possibility of loading the support frames with force greater than $40 \mathrm{kN}$. It should be noted that in most cases, the manufacturers declare that the load capacity of the rail joint is $50 \mathrm{kN}$. Of course, the permissible load of the support arches is increased upon consent and under the conditions specified by the Mining Department Manager. Calculations are carried out for sets equipped only with their own brakes or also with emergency brake trolleys. The value of the permissible speed depends on whether the set transports materials or people. In the situation where relevant regulations contain very few provisions, and the specialist literature is scarce, this proven calculation method with a calculation sheet enables designing suspended monorail transportation systems while maintaining the required level of safety. One year after implementation, it can be concluded that the method and the calculation sheet fulfil their function. During the inspection of the transport systems and related documentation by the mining supervision authorities, no irregularities were found. The method in question indicates only one proper way of performing calculations. Owing to this, any doubts as to the safe use of the suspended monorail transport systems are greatly limited. Of course, the method itself does not release its users from the obligations arising from other regulations and good mining practices, i.e. regular inspection of the route or the technical 
condition of the support, with special regard to the reinforcements used. A practical example of application can be found in the publication (Bołoz et al., 2020).

After making the calculations, an important part of the work is to check whether the equipment being part of the transport system has been properly selected and meets the requirements resulting from the calculations.

\section{References}

Alix, T., Benama, Y. and Perry. N. (2019). A framework for the design of a Reconfigurable and Mobile Manufacturing System. Procedia Manufacturing, 35, pp. 304-309.

Antoniak, J. (1980). Maszyny Górnicze, Część III, Transport kopalniany. Katowice: Wydawnictwo „Śląsk”.

Blatnicky M., Dizo J., Saga M., Gerlici J., Kuba E. (2020). Design of a Mechanical Part of an Automated Platform for Oblique Manipulation, Applied Sciences-Basel, Vol.10, Issue 23, Article No: 8467, DOI: 10.3390/app10238467, 2020

Bołoz, Ł., Ciepliński, Z. and Knapski, R. (2020). Wdrożenie metody obliczeń statycznych i dynamicznych wybranych parametrów trakcyjnych kolejek podwieszonych w warunkach PG Silesia. Przegląd Górniczy, 10, pp. 1-11.

Brahimi, N., Dolgui, A., Gurevsky, E. and Yelles-Chaouche, A. R. (2019). A literature review of optimisation problems for reconfigurable manufacturing systems, IFAC-PapersOnLine, 52(13), pp. 433-438.

Draganová, K., Semrád, K., Spodniak, M., Cúttová, M. (2020). Innovative analysis of the physical-mechanical properties of airport conveyor belts. Transportation Research Procedia, 51, pp. 20-27. DOI 10.1016/j.trpro.2020.11.004

Figiel, A., Klačková, I. (2020). Safety requirements for mining complexes controlled in automatic mode. In Journal Acta Montanistica Slovaca 2020, Volume 25, 3; ISSN 1335-1788, DOI 10.46544/AMS.v25i3.13.

Chanda, E. K. and Besa, B. (2011). Acomputer simulation model of a mining system for decline development. International Journal of Mining, Reclamation and Environment, 2011, 25(1), pp. 52-68.

Gutarevych, V. (2012). A mathematical model study of suspended monorail. Transport Problems, 7(3), pp. 6166.

Gutarevych, V. (2014). Dynamic model of movement of mine suspended monorail. Transport problems, 9(1), 1318

Kuric, I., Klačková, I., Nikitin, Y.R., Zajačko, I., Císar, M., Tucki, K. (2021). Analysis of diagnostic methods and energy of production systems drives, In Journal; Processes, MDPI, 9, 843, DOI.org/10.3390/pr9050843

Kuric, I., Tlach, V., Sága, M., Císar, M., Zajačko, I. (2021). Industrial robot positioning performance measured on inclined and parallel planes by double ballbar. In Journal: Applied Science-Basel, eISSN: 2076-3417, volume 11, Issue 4, article number: 1777, pp. 1-18, 2021

Lee, C.H., Kim, C.W., Kawatani, M., Nishimura, N. and Kamizono, T. (2005). Dynamic response analysis of monorail bridges under moving trans and riding comfort of trans. Engineering Structures, 27(14), pp. 19992113

Muravev, V.V., Muraveva, O.V., Volkova, L.V., Sága, M. and Ságová, Z. (2019). Measurement of residual stresses of locomotive wheel treads during the manufacturing technological cycle. Management Systems in Production Engineering, 27(4), pp. 236-241

Pástor, M., Živčák, J., Púškár, M., Lengvarský, P., Klačková, I. (2020). Application of Advanced Measuring Methods for Identification of Stresses and Deformations of Automotive Structures. In Journal; Applied Sciences - Basel 2020, Volume 10, Issue 21, article number 7510, MDPI, ISSN 2076-3417.

Pieczora, E. (2008). Forecast of development of rail transportation systems used in hard coal mine underground. Gospodarka surowcami mineralnymi - mineral resources management. 24(1), pp. 221-232.

Pieczora, E. and Suffner, H. (2013). Rozwój lokomotyw do kopalnianych kolei podziemnych. Maszyny Górnicze, 31(2), pp. 45-54.

Pieczora, E. and Suffner, H. (2017). Development of mine underground transportation with use of suspended monorails. Mininig - Informatics Automation and Electrical Engineering, 55(4), pp. 96-106.

Pytlik, A. (2019). Tests of steel arch and rock bolt support resistance to static and dynamic loading induced by suspended monorail transportation. Studia Geotechnica et Mechanica, 41 (2), pp. 1-12.

Saga M., Blatnicky M., Vasko M., Dizo J., Kopas P., Gerlici J. (2020). Experimental Determination of the MansonCoffin Curves for an Original Unconventional Vehicle Frame, Materials, Vol.13, Issue 20, Article No: 4675, DOI: 10.3390/ma13204675, 2020

Semrád, K., Draganová, K., Košcák, P., Cernan, J. (2020). Statistical prediction models of impact damage of airport conveyor belts. Transportation Research Procedia, 51, pp. 11-19. DOI 10.1016/j.trpro.2020.11.003

Szewerda, K., Tokarczyk, J., Božek, P., Michalak, D. and Drwięga, A. (2020). Vibrations diagnostics and analysis in operator's and passenger cabins of a suspended monorail. Acta Montanistica Slovaca, 25(2), pp. 150158. 
Tokarczyk, J. (2016). Method for identification of results of dynamic overloads in assessment of safety use of the mine auxiliary transportation system. Archives of Mining Sciences, 61(4), pp. 765-777.

Tokarczyk, J. and Dudek, M. (2020). Methods for computer aiding the configuration and assessment of auxiliary mine transportation means. Management Systems in Production Engineering, 28(4), pp. 268-275.

Tokarczyk, J. and Kania, J. (2016). Systems and tracks of self-powered suspended monorails for transportation of people in horizontal workings and workings with inclination up to $45^{\circ}$. Mininig - Informatics Automation and Electrical Engineering, 54(3), pp. 31-39.

Tokarczyk, J., Rotkegel, M., Pytlik A. and Niedworok, A. (2020). Research on the impact of forces and acceleration during the riding and braking of a suspended monorail. Archives of Mining Sciences, 65(2), pp. 399-414.

True, H. (2009). Dynamics of Railway and Rail/Wheel Contact. Dynamical Analysis of Vehicle Systems, 497, pp. 75-128.

Turygin, Y., Bozek, P., Abramov, I. and Nikitin, Y. (2018). Reliability determination and diagnostics of a mechatronic system. In Advances in Science and Technology Research Journal. 12(2), pp. 274-290. 